\title{
Optimization of multiple trait selection in western hemlock (Tsuga heterophylla (Raf.) Sarg.) including pulp and paper properties
}

\author{
Milosh Ivkovich $^{*}$ and Mathew Koshy \\ Department of Forest Sciences, University of British Columbia, Vancouver, BC V6T1Z4, Canada
}

(Received 5 July 2001; accepted 14 January 2002)

\begin{abstract}
Options for incorporating wood quality in British Columbia's hemlock breeding program were investigated. Seventy half-sib families were examined. Attention was given to quantitative variation in tracheid characteristics and its effects on pulp and paper properties. Based on the existing knowledge of relationships between fibre properties and paper quality, the potential gain in yield and wood quality was estimated for different selection strategies. Improvement without much trade-off was possible for volume and tensile strength of pulp and paper. Significant trade-offs would be required to improve the volume, tear strength of paper and strength of mechanical pulp. Therefore, multiobjective optimization would be beneficial. Conservative selection strategies seem realistic, and compromises with gain in volume growth may be profitable. The potential loss arising from the uncertainty about economic values for objectives can be overcome by using different selection indices in multiple breeding populations.
\end{abstract}

Tsuga heterophylla / wood quality / index selection / breeding / optimization

Résumé - Optimisation de la sélection multi-caractères pour les propriétés de la pâte et du papier chez (Tsuga heterophylla (Raf.) Sarg.). Nous avons étudié plusieurs stratégies d'introduction de la qualité du bois dans le programme d'amélioration génétique de Tsuga heterophylla en Colombie Britannique. Soixante-dix familles de demi-frères ont été examinées. Nous avons observé la variation quantitative des caractéristiques des trachéides et analysé ses effets sur les propriétés de la pâte et du papier. En nous basant sur la connaissance des liens entre les propriétés des fibres et la qualité du papier, nous avons estimé le gain potentiel pour le rendement et la qualité du bois pour différentes stratégies de sélection. Il est possible d'améliorer simultanément sans faire beaucoup de compromis le volume et la résistance à la traction de la pâte et du papier. Des compromis importants sont nécessaires pour améliorer simultanément le volume, la résistance à la déchirure du papier, et la résistance à la tension de la pâte TMP. En conséquence, l'optimisation multi-objectifs parait intéressante. Les incertitudes sur les poids économiques des caractères, potentiellement responsables de pertes, peuvent être écartées si on utilise des index de sélection différents sur des populations d'amélioration multiples.

Tsuga heterophylla / qualité du bois / indice de sélection / amélioration génétique / optimisation

\section{INTRODUCTION}

Besides selection for high volume production and pest resistance, wood quality is one of the major considerations in tree improvement programs. Unfortunately, in conifers, there is often a strong negative genetic correlation between radial growth rate and some wood properties. This accounts for difficult genetic manipulation of these growth and wood traits in the process of tree breeding. Breeding for volume could cause reduction in wood density, which could in turn cause reduction in dry-weight of wood, lower pulp yield, and change in quality of paper or lumber products. Although the wood density is probably one of the major factors that influence the pulp yield, there are other wood properties important for the pulp production. These properties include fibre length and coarseness, microfibril angle, and some others [9, 25].

\footnotetext{
* Correspondence and reprints

Tel.: 02384178 73; fax: 02384178 79; e-mail: ivkovich@orleans.inra.fr

Current address: INRA, Centre de Recherches d'Orléans, Avenue de la Pomme de Pin, BP 20169, Ardon, 45166 Olivet Cedex, France
} 
It is apparent now in tree breeding that more attention ought to be given to the simultaneous improvement of growth and wood quality traits. For example, thick-walled fibres give higher pulp yield, but the produced pulp is coarser and its quality may not be satisfactory. The utility of improving fibre length is also questioned, since in conifers fibres are already relatively long and increasing the length through genetic improvement may not warrant the effort. However, breeding might be necessary to maintain the current fibre lengths, especially in short rotation plantations, where mostly juvenile wood is produced. This approach would depend on what type of end product is made from improved trees. Generally, the utility of incorporating a certain trait into a tree improvement program should be assessed interactively by considering the genetic aspects such as heritability and genetic correlations together with the economic objective functions including that trait $[2,10,26]$.

The relative importance of traits considered for simultaneous selection can be substantially influenced by the property of the objective function that relates the traits to product quality. Theoretical and semi-empirical models have been developed, which relate fibre properties to properties of pulp and paper $[18,19,22]$. Theoretically developed formulations are less dependent on a particular process or product type, and therefore may be desirable for use as breeding objective functions. Based on the relationships between fibre properties and paper quality, the effectiveness of selection for the value of final products made from improved trees was examined.

Multiple index selection has been viewed as possibly the most viable option for incorporating multiple traits and multiple objectives into a tree improvement program [16]. The breeding population can be divided into several smaller ones, and, within each population, a different selection index can be applied. By doing so, a whole array of possible future alternatives can be explored. However, this technique has not been applied in the existing hemlock breeding programs. Its advantages and disadvantages needed to be evaluated relatively to the other more conventional techniques.

The purpose of this study was to examine the potential for multiple trait improvement in western hemlock (Tsuga heterophylla (Raf.) Sarg.). The particular objectives were:

(a) to identify goals of selection and appropriate objective functions;

(b) to derive economic weights for traits based on maximization of each particular objective function, with constraint defined as the maximum genetic response;

(c) to examine the relationship between various objective functions during the process of single and multiple objective optimization of selection;

(d) to derive different alternatives for multiple selection indices involving different objective functions; (e) to present results, including advantages and disadvantages of each selection alternative, in such a manner so that decision-makers can choose from an array of possibilities.

\section{MATERIALS AND METHODS}

\subsection{Quantitative assessment of wood anatomy}

Seventy western hemlock half-sib families, which belong to the breeding population of the BC Ministry of Forests ongoing tree-improvement program, were evaluated. These families were laid out in a field trial at Bonanza in 1982. For each family, eight trees from each of four replications were sampled in 1999. Average (weighted by ring area) anatomical characteristics of five outermost rings were used in this study. Quantitative assessment of tracheid characteristics by measuring cross-sectional dimensions was done following the technique of Ivkovich and Koshy [7]. Transverse sections, $12 \mathrm{~m} \mu$ thick, were prepared using a sliding microtome, stained with aniline safranin, and mounted with Cytoseal ${ }^{\mathrm{TM}}$. Monochrome images were captured with a video camera and analysed by the SigmaScanPro ${ }^{\circledR}$ image processing software [8].

Estimates of variance and covariance components were obtained using the program package Quercus [20], which facilitates the multiple-trait restricted maximum likelihood (REML) algorithm for quantitative genetic data $[3,23]$. The additive genetic $(\boldsymbol{G})$ and the phenotypic (denominator of heritability) variance-covariance matrix $(\boldsymbol{P})$, on which all further calculations were based, were calculated on an individual tree basis. Genetic response in derived traits such as fibre perimeter $(\mathrm{P})$, and coarseness $(\mathrm{C})$ were calculated as a function of genetic responses in their component traits. These traits were therefore included in the objective functions for selection.

\subsection{Definitions of objective functions}

Growth and wood fibre characteristics were combined to form the following objective functions related to pulp and paper properties.

Dry-weight on a per ring basis was determined as the product of ring volume (VOL) (assuming circular rings of unit height), ratio of double wall thickness to cell size (R), and wood basic density $\left(\rho=1.54 \mathrm{~g} \mathrm{~m}^{-3}\right)$ :

$$
\mathrm{DW}=\mathrm{VOL} \times \mathrm{R} \times \rho
$$

Tensile strength of pulp wet-webs $\left(\mathrm{T}_{\mathrm{ww}}\right)\left(\mathrm{Nm} \mathrm{g}^{-1}\right)$ was defined according to the quantitative theory of the strength of wet-webs [19]:

$$
\mathrm{T}_{\mathrm{Ww}}=\frac{\mathrm{b} \times \mathrm{P} \times \mathrm{L} \times \mathrm{RBA}}{12 \times \mathrm{C}}
$$

where $b$ is the shear strength of the fibre-fibre bond (constant assigned $2.3 \times 10^{4} \mathrm{~N} \mathrm{~m}^{-2}$ ), $\mathrm{P}$ is perimeter of the average fibre cross-section $(\mathrm{m}), \mathrm{L}$ is fibre length $(\mathrm{m}), \mathrm{RBA}$ is relative bonded area in the sheet (constant assigned 0.50 ), and $\mathrm{C}$ is fibre coarseness $\left(\mathrm{g} \mathrm{m}^{-1}\right)$ (i.e. weight per unit length, which is proportional to cross-sectional area of fibre wall).

Tensile strength of paper $\left(\mathrm{T}_{\mathrm{p}}\right)\left(\mathrm{Nm} \mathrm{g}^{-1}\right)$ in an explicit equation was derived by Page [18]:

$$
\frac{1}{\mathrm{~T}_{\mathrm{p}}}=\frac{9}{8 \times \mathrm{Z}}+\frac{12 \times \mathrm{CSA} \times \rho}{\mathrm{b} \times \mathrm{P} \times \mathrm{L} \times \mathrm{RBA}}
$$


where $\mathrm{Z}$ is zero-span tensile strength (a measure of fibre strength assigned $100 \mathrm{Nm} \mathrm{g}^{-1}$ ), CSA is average cross-sectional area of fibre wall fraction $\left(\mathrm{m}^{2}\right), \rho$ is density of cellulose $\left(1.54 \mathrm{~g} \mathrm{~m}^{-3}\right)$, b is shear strength of the fibre-fibre bond (constant assigned $5.9 \times 10^{6} \mathrm{~N} \mathrm{~m}^{-2}$ ), $\mathrm{P}$ is perimeter of the average fibre cross-section $(\mathrm{m}), \mathrm{L}$ is fibre length (m), and RBA is relative bonded area in the sheet (constant assigned $0.90)$.

Tearing resistance of paper (TR) for weakly bonded sheets has a straight-line relationship with the formula defined by Clark [1]:

$$
\mathrm{TR}=\mathrm{K}_{1} \times \mathrm{Z}^{0.2} \times \mathrm{L}^{1.5} \times \mathrm{C}^{1.0} \times \mathrm{S}^{0.5} \times \mathrm{V}^{0.1}
$$

where $\mathrm{K}_{1}$ is a constant, $\mathrm{Z}$ is intrinsic fibre strength, $\mathrm{L}$ is fibre length, $\mathrm{C}$ is fibre coarseness, $\mathrm{S}$ is cohesiveness, and $\mathrm{V}$ is bulk or specific volume.

Burst fracture resistance $(\mathrm{BF})$ for weakly bonded sheets gives a straight-line relationship with the formula defined by Clark [1]:

$$
\mathrm{BF}=\mathrm{K}_{1} \times \mathrm{Z}^{0.1} \times \mathrm{L}^{1.0} \times \mathrm{C}^{-1.0} \times \mathrm{S}^{0.5} \times \mathrm{V}^{-0.1}
$$

where abbreviations are the same as for the previous formula.

Strength of mechanical pulp $\left(\mathrm{T}_{\mathrm{m}}\right)$ was derived by Rudie [22], using a simple formula that under certain conditions gives a straight-line relationship with pulp breaking length, at a fixed specific energy consumption:

$$
\mathrm{T}_{\mathrm{m}}=\mathrm{P} / \mathrm{CSA}
$$

where $\mathrm{P}$ is fibre perimeter of the average fibre cross-section, CSA is average cross-sectional area of fibres' solid fraction.

\subsection{Maximization with genetic responses as constraints}

Parent tree selection was done based on their half-sib progeny performance. For selection to be maximally efficient, relative economic weights on different traits according to particular objective functions are needed. Optimal index weights for selection indices with non-linear profit functions can be derived using the method of Itoh and Yamada [6]. (Linearisation of objective functions based on Taylor series approximation about means after selection lead in some cases to selection of different sets of parents.)

Expected selection responses in tracheid characteristics $(\boldsymbol{d})$ form an ellipsoid and it is defined by:

$$
d^{\prime} G^{-1} P G^{-1} d=i^{2}
$$

where $\boldsymbol{G}$ is genetic variance-covariance matrix, $\boldsymbol{P}$ is phenotypic variance-covariance matrix, and $i$ is selection intensity. Among all $d^{\prime}$ 's which satisfy the above equation we have to find those which maximize expectation:

$$
f(E(\mathrm{x}))=f(\mu+d)
$$

where $\mu$ is the vector of population means.

After obtaining optimum $\boldsymbol{d}$ we can get the index weights $\boldsymbol{b}$ for tracheid characteristics from

$$
\boldsymbol{b}=\boldsymbol{G}^{-1} \boldsymbol{d}
$$

From coefficients $\boldsymbol{b}$ the implied economic weights ( $\boldsymbol{a})$ can be obtained as follows [4]:

$$
\boldsymbol{a}=\left(\boldsymbol{G}^{\prime} \boldsymbol{G}\right)^{-1} \boldsymbol{G}^{\prime} \boldsymbol{P} \boldsymbol{b}
$$

The expected response in various objective functions can be obtained by this method and sets of parents selected based on different indices compared.

Iterative maximization of single objective functions was done by the Solver option in Microsoft Excel ${ }^{\circledR}$ (1997). Microsoft Excel Solver uses the Generalised Reduced Gradient (GRG2) non-linear optimization code $[11,12]$. When more than one objective function is used, then multiobjective optimization was employed to maximize genetic gain [14]. An interactive method for multiobjective optimization problems NIMBUS (Nondifferentiable Interactive Multiobjective Bundle-based Optimization System) can be used for finding non-dominated (Pareto optimal) set of solutions for considered functions [17]. The problems to be solved are of the form:

$$
\begin{array}{cl}
\operatorname{maximize} & \left\{f_{1}(\mathbf{x}), \ldots, f_{\mathrm{k}}(\mathbf{x})\right\} \\
\text { subject to } & g_{1}(\mathbf{x}) \leq 0 \ldots \\
& g_{\mathrm{m}}(\mathbf{x}) \leq 0 \\
& \mathbf{x}^{l} \leq \mathbf{x} \leq \mathbf{x}^{u}
\end{array}
$$

where $\mathrm{k}$ is the number of the objective functions, $\mathrm{m}$ is the number of the non-linear constraints (ellipsoid of maximum selection responses), and $\mathbf{x}$ is the criterion vector and its lower and upper bounds are $\mathrm{n}$-dimensional vectors.

The result of the multiobjective optimization is a criterion vector, whose components are the values of the objective functions at points $\mathbf{x}$. A criterion vector is "Pareto optimal" if none of its components can be improved without impairing at least one of the other components. When optimizing the functions individually and creating the vector of these values, the Ideal Criterion Vector (ICV) is obtained. The ICV represents the upper bounds of the criterion values in the set of Pareto optimal solutions. On the other hand, "Nadir" vector consists of component values for the "worst case" scenario, i.e. the lower bounds of the criterion values in the Pareto optimal set [14].

\subsection{Selection scenarios for different breeding strategies}

The results of the optimization processes were used as a basis for evaluating selection scenarios in different breeding strategies. Firstly, optimizing selection for a single objective function within a single breeding population at a time was considered. Secondly, multiple objective functions within a single breeding population were considered, and the solutions represented the range of necessary trade-offs between improvement in different objective functions depending on how much emphasis was placed on each particular objective. The trade-offs were graphically presented. Allocation of objectives according to specific criteria was examined more closely. Those criteria were maximum possible improvement in either objective function (MaxiMax), maximized average value (MaxiAvr), maximized minimum improvement of all objectives (MaxiMin), and minimised maximum loss (MiniMax). Because of the uncertainty about relative values of objective functions in the future, those options represent different risk-management strategies, according to particular attitudes towards risk. Finally, selection for multiple objective functions using two or more breeding populations was considered. When uncertainty about the objective functions exists, a diversified breeding population and multiple-index selection technique developed by Namkoong [15] can be employed as a risk reduction strategy.

\section{RESULTS AND DISCUSSION}

Results presented in this paper should be viewed with caution. They are based on a limited sample from western hemlock breeding populations and cannot be generalized. Due to the limited scope of this study, only limited sensitivity analyses were performed and confidence limits on obtained 
statistics are not given here. Therefore different selection scenarios are distinguished using only the point estimates of selection index weights instead of their full distributions. More extensive sensitivity analyses should involve generating random matrices from an assumed distribution of phenotypic and genetic variance-covariance matrices, and varying parameters of objective function.

\subsection{Optimization of single objective functions}

Basic traits for our analyses were ring width (RW), tracheid cross-sectional area (CSA), tracheid size (CS), ratio of double cell wall to cell size (R), and fibre length (L). Estimates of their population means and standard deviations, together with heritabilities, genetic and phenotypic correlations, are given in table I. Expected genetic response $(\Delta)$ after one generation of truncation selection $(i=1)$ was calculated based on gain equations for multiple traits and the following results were obtained.

Selection within single breeding population for volume $\left(\mathrm{I}_{\mathrm{VOL}}\right)$, as a single objective, could result in significant improvements, positively influencing dry weight (DW) and tear strength of paper, but negatively influencing other pulp and paper characteristics (table II). Selection for volume would result in an increase in RW, CS and CSA, but in a negative change in $\mathrm{R}$ and $\mathrm{L}$ (table III). This is in agreement with results obtained by King et al. [10].

Selection for volume with a restriction of no change in wood density $\left(\mathrm{I}_{\mathrm{VOL} \_\mathrm{R}}\right)$ would slightly reduce genetic gain in volume and dry-weight in comparison to direct selection $\left(\mathrm{I}_{\mathrm{VOL}}, \mathrm{I}_{\mathrm{DW}}\right)$. This selection will also have a strong positive impact on tear strength of paper. However, it will negatively affect other pulp and paper properties, especially the strength of mechanical pulps and burst factor (table II). Except for no change in tracheid density, restricted selection would result in increase in all component anatomical traits (table III).

Selection for wood dry-weight $\left(\mathrm{I}_{\mathrm{DW}}\right)$ would reduce genetic gain in volume. This selection would give an even higher improvement in TR than selection on $\mathrm{I}_{\mathrm{VOL} \_\mathrm{R}}$. However, it will negatively affect other pulp and paper properties, especially the strength of mechanical pulps, and burst factor (table II). Dry-weight selection would result in improvement in all anatomical component traits (table III). This result is in agreement with the suggestion that use of dry or gross-weight yield instead of volume as the trait for selection would preserve wood density [24]. Although one family (parent 266) had consistently the highest rank, selection based on different selection indices $\left(\mathrm{I}_{\mathrm{VOL}}, \mathrm{I}_{\mathrm{VOL} \_\mathrm{R}}, \mathrm{I}_{\mathrm{DW}}\right)$ would generally result in change of ranks for parent trees.

\subsection{Optimization of multiple objectives}

Simultaneous improvement of growth and pulp and paper properties would require trade-offs. Therefore, multiobjective optimization would be beneficial. Improvement without
Table I. Population means \pm standard deviations (SD) for ring width (RW), cross-sectional area (CSA), tracheid size (CS), ratio of double cell wall to cell size (R), and fibre length (L). And a matrix with heritabilities (on diagonal, bold), genetic (above diagonal), and phenotypic (below diagonal) correlations.

\begin{tabular}{|c|c|c|c|c|c|}
\hline & RW & CSA & $\mathrm{CS}$ & $\mathrm{R}$ & $\mathrm{L}$ \\
\hline Mean \pm SD & $\begin{array}{c}2.78 \pm 0.82 \\
\mathrm{~mm}\end{array}$ & $\begin{array}{c}140.7 \pm 20.6 \\
\mu \mathrm{m}^{2}\end{array}$ & $\begin{array}{c}24.6 \pm 2.6 \\
\mu \mathrm{m}\end{array}$ & $0.235 \pm 0.033$ & $\begin{array}{c}2.36 \pm 0.74 \\
\mathrm{~mm}\end{array}$ \\
\hline RW & 0.193 & 0.396 & 0.717 & -0.551 & 0.048 \\
\hline CSA & 0.392 & 0.746 & 0.777 & 0.246 & 0.620 \\
\hline $\mathrm{CS}$ & 0.662 & 0.820 & 0.422 & -0.410 & 0.394 \\
\hline $\mathrm{R}$ & -0.690 & -0.256 & -0.750 & 0.478 & 0.300 \\
\hline $\mathrm{L}$ & 0.144 & 0.497 & 0.446 & -0.190 & 0.892 \\
\hline
\end{tabular}

Table II. Correlated genetic response $(\Delta)$ in pulp and paper properties resulting from one generation of truncation selection $(i=1)$. Selection was based on four indices: $\mathrm{I}_{\mathrm{VOL}}$ that maximizes response in volume (VOL), $\mathrm{I}_{\mathrm{VOL} \_\mathrm{R}}$ that maximizes response in volume and places restriction on change in $\mathrm{R}, \mathrm{I}_{\mathrm{DWT}}$ that maximizes response in dry-weight (DWT) and $\mathrm{I}_{\text {MaxiMin }}$ that maximizes minimum improvement in functions VOL, TR and $\mathrm{TS}_{\mathrm{m}}$. Pulp and paper properties are tensile of wet-webs $\left(T_{w w}\right)$, tensile of paper $\left(T_{p}\right)$, tensile strength of mechanical pulp $\left(\mathrm{T}_{\mathrm{m}}\right)$, tear strength of weakly bonded paper (TR) and burst factor of weakly bonded paper (BF). Genetic responses are given as a percentage of the present mean.

\begin{tabular}{lccccccc}
\hline & \multicolumn{7}{c}{ \% correlated genetic responses } \\
\cline { 2 - 8 } Index & $\Delta$ VOL & $\Delta \mathrm{DW}$ & $\Delta \mathrm{TS}_{\mathrm{ww}}$ & $\Delta \mathrm{TS}_{\mathrm{p}}$ & $\Delta \mathrm{TS}_{\mathrm{m}}$ & $\Delta \mathrm{TR}$ & $\Delta \mathrm{BF}$ \\
\hline $\mathrm{I}_{\text {VOL }}$ & 16.8 & 7.74 & -1.05 & -0.17 & -0.65 & 4.48 & -5.27 \\
$\mathrm{I}_{\text {VOL-R }}$ & 14.5 & 10.0 & -0.71 & -0.27 & -5.08 & 15.12 & -6.76 \\
$\mathrm{I}_{\text {DWT }}$ & 15.4 & 10.8 & -1.26 & -0.28 & -6.82 & 16.18 & -6.86 \\
$\mathrm{I}_{\text {MaxiMin }}$ & 11.6 & 6.92 & 1.09 & 0.14 & 0.19 & 7.93 & -3.21 \\
\hline
\end{tabular}

Table III. Genetic response $(\Delta)$ in anatomical (component) traits arising from one generation of truncation selection $(i=1)$. Selection was based on four indices: $\mathrm{I}_{\mathrm{VOL}}$ that maximizes response in volume (VOL), $\mathrm{I}_{\mathrm{VOL} \_\mathrm{RD}}$ that maximizes response in volume and places restriction on change in $\mathrm{RD}$, and $\mathrm{I}_{\mathrm{DWT}}$ that maximizes response in dry-weight (DWT) and $\mathrm{I}_{\text {MaxiMin }}$ that maximizes minimum improvement in functions VOL, TR and $\mathrm{TS}_{\mathrm{m}}$. Component traits are ring width $(\mathrm{RW})$, cell cross-sectional area (CSA), perimeter $(\mathrm{P})$, ratio of double wall thickness to cell size (R) and fibre length (L). Genetic-response is given as percentage of the present mean. Estimated economic-weights are given in brackets.

\begin{tabular}{lccccc}
\hline \multirow{2}{*}{ Index } & \multicolumn{5}{c}{$\%$ trait responses and economic weights } \\
\cline { 2 - 6 } & $\Delta \mathrm{RW}$ & $\Delta \mathrm{CSA}$ & $\Delta \mathrm{P}$ & $\Delta \mathrm{R}$ & $\Delta \mathrm{L}$ \\
\hline $\mathrm{I}_{\text {VOL }}$ & 8.50 & 5.14 & 4.42 & -3.84 & -0.40 \\
& $(6.12)$ & $(0.00)$ & $(0.00)$ & $(0.00)$ & $(0.00)$ \\
$\mathrm{I}_{\text {VOL-RD }}$ & 7.00 & 12.0 & 5.44 & 0.00 & 4.40 \\
& $(7.12)$ & $(0.00)$ & $(0.00)$ & $(36.2)$ & $(0.00)$ \\
$\mathrm{I}_{\text {DWT }}$ & 7.54 & 13.14 & 5.42 & 3.11 & 5.41 \\
& $(7.14)$ & $(0.00)$ & $(0.00)$ & $(43.7)$ & $(0.00)$ \\
$\mathrm{I}_{\text {MaxiMin }}$ & 6.10 & 4.29 & 4.48 & -4.62 & 0.74 \\
& $\left(6.27 \times 10^{-3}\right)$ & $\left(-5.97 \times 10^{-2}\right)$ & $(1.34)$ & $(0.00)$ & $(0.40)$ \\
\hline
\end{tabular}


much trade-off was possible for volume and tensile strength of chemical pulp and paper. Significant trade-offs would be required, however, for simultaneous improvement of volume, tensile strength of mechanical pulp, and tear factor of paper (table II). The Ideal Criterion Vector (ICV) and Nadir vectors for the latter three objectives were obtained. The ICV tells us the best solution that exists for each objective, when the functions are treated independently. Nadir vector, on the other hand, consists of component values for the "worst case" solution scenario.

$\begin{array}{lcc} & \text { ICV }(\%) & \text { Nadir }(\%) \\ \text { VOL } & 16.83 & 0.657 \\ \text { TM } & 9.922 & -7.453 \\ \text { TR } & 16.99 & -5.904\end{array}$

Accommodating multiple objective functions within a single breeding population requires allocation of objectives according to some particular criteria, (i.e. different riskreduction strategies). A set of Pareto-optimal solutions for objective functions VOL, TM and TR was generated using multiple objective optimization, and is given in figure 1. Depending on the choice of risk-reducing strategy different alternatives can be chosen from this set. Maximum average gain (MaxAver) and minimum potential loss (MiniMax) would be obtained by choosing the alternative 1 . The highest maximal improvement in a property (TR) can be achieved by choosing the alternative 20. Maximum simultaneous improvement in VOL, TM and TR (MaxiMin) can be achieved by choosing the alternative 9. For the MaxiMin alternative, response in functions and individual component traits, together with corresponding economic weights, are given in tables II and III. The most conservative MaxiMin option was separated from the other options, and it resulted in different sets of selected parents. If higher weight were placed on

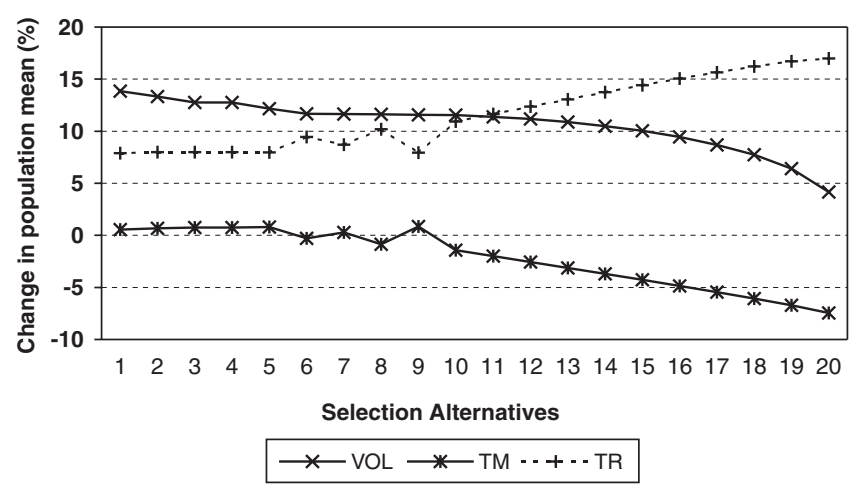

Figure 1. Twenty different selection alternatives (set of Pareto-optimal solutions) representing trade-offs necessary for simultaneous improvement in volume growth (VOL), simultaneous response in tensile strength of mechanical pulp (TM), and in tear strength of paper (TR) based on multiobjective optimization. The improvement is expressed as a proportion of the present mean, at the selection intensity of $i=1$. certain objectives, different solutions would be obtained. Any conservative options should be further justified because compromises with volume growth may not be beneficial. This justification needs to be based on a sound economic analysis.

\subsection{Multiple breeding populations}

Under uncertainty about future values of breeding objectives, introduction of additional populations could also be considered. The breeding population can be divided into several smaller ones, and within each population, a different selection index can be applied. The utility of having extra populations in a breeding program would depend on the relationship between objective functions. Theoretically, total expected loss would be reduced if two or more populations could be formed, and two selection indices derived with two different weights on objectives. Aggregated expected value of such a set of populations would always exceed the value of one population at a single optimum $[15,21]$. Expected genetic response in volume and tear strength showed a significant trade-off, and risk-reduction strategies, including diversification through multiple breeding population system, may be justified.

If the relative values of objective functions are estimated with more precision, further optimization can be obtained through an iterative process using the multiobjective method NIMBUS. Here a range of alternatives is presented and choosing between alternatives by classification of functions would depend on a decision-maker's preferences. Sensitivity between the two points of interest could be checked by inserting a number of new alternatives. Optimization of a breeding system would depend on both the relative value assigned to each function, and on decision-maker's attitude toward risk. If some expert knowledge is available, the value of each function can be predicted and scaled to, for example, the monetary value at the time of harvesting. If this can be done with some certainty, probabilities can be assigned. If uncertainty about the relative importance of particular objectives stays high, then assigning objective functions to diversify breeding populations could be advantageous [5].

\section{CONCLUSIONS}

The complexity of factors influencing pulp and paper production, development of new technologies, and the ever-changing market conditions often cause tree breeders to choose conservative strategies for selection. In the situation of high uncertainty, when the objective function remains unknown and economic weights unpredictable, the use of MaxiMin solution or restricted selection indexes has been suggested $[10,13,16]$. The solutions are highly conservative options that may cause losses in potential genetic gain. The consequences of applying the conservative selection 
techniques, which avoid declaring breeding objectives a priori, were investigated here.

Based on the existing knowledge of relationships between fibre properties and paper quality, the expected response in volume, wood dry-weight, and pulp and paper quality was estimated when different selection techniques were used. Although the obtained results ware lacking in statistical rigour, some general trends were apparent. Simultaneous improvement of volume growth and paper properties would require trade-offs and multiobjective optimization would be beneficial. Improvement without much trade-off would be possible for volume and tensile strength of pulp and paper. But significant trade-offs would be required to improve volume, tear factor of paper and strength of mechanical pulp. The conservative options (MaxiMin) seemed realistic and compromises with gain in volume growth may be necessary. However, if different values were assumed for some objectives, different solutions would have been obtained.

The potential loss arising from the uncertainty about economic values for objectives can be partially overcome by using multiple selection indices in multiple breeding populations. By giving each population a different breeding objective, a whole array of possible future alternatives can be explored. The utility of having extra populations in a breeding program would depend on the relationship between objective functions and the decision-maker's attitude towards risk. Total expected loss would be reduced if two or more populations could be formed and selection indices derived for each population, according to different objectives.

Acknowledgements: The completion of this research would have been impossible without the expertise and efforts of Ben Raj and Dr. Domingus Yawalata. Kind thanks need also to be awarded to Dr. Philippe Rozenberg for his encouragement, translation of the summary, and general comments. This study was funded by an FRBC research grant FR 96/97-196.

\section{REFERENCES}

[1] Clark J. d'A., Pulp technology and treatment of paper, 2nd ed., Miller Freeman Publicatoins, San Francisco, 1985.

[2] Chantre G., Rozenberg P., Baonza V., Macchioni N., Le Turcq A., Rueff M., Petit Conil M., Heois B., Genetic selection within Douglas fir (Pseudotsuga menziessi) in Europe for papermaking uses, in: Abstracts of the International Conference on: Wood, Breeding, Biotechnology and Industrial Expectations, June 11-14, 2001, Bordeaux, France, p. 38.

[3] Cockerham C.C., Wier B.S., Quadratic analysis of reciprocal crosses, Biometrics 33 (1977) 187-203.
[4] Gibson J.P., Kennedy B.W., The use of constrained selection indexes in breeding for economic merit, Theor. Appl. Genet. 80 (1990) 801-805.

[5] Harwood J.L., Managing risk in farming: concepts, research, and analysis, USDA Economic Research Service, Agricultural economic report No 774, (1999).

[6] Itoh Y., Yamada Y., Linear selection indices for non-linear profit functions, Theor. Appl. Genet. 75 (1988) 553-560.

[7] Ivkovich M., Koshy M.P., Wood density measurement: comparison of X-ray, photometric, and morphometric methods, in: Proceedings of the 26th Biannual Meeting of the Canadian Tree Improvement Association (CTIA/IUFRO), International Workshop on Wood Quality, Quebec City, Zhang S.Y., Gosselin R., Chauret G. (Eds.), 1997, pp. II 55-58.

[8] Jandel Corporation, SigmaScanPro ${ }^{\circ}$ Automated Image Analysis Software, User's Manual, Jandel Corporation, 1995.

[9] Kennedy R.W., Coniferous wood quality in the future: concerns and strategies, Wood. Sci. Tech. 29 (1995) 321-338.

[10] King J.N., Cartwright C., Hatton J., Yanchuk A.D., The potential of improving western hemlock pulp and paper quality I. Genetic control and interrelationships of wood and fibre traits, Can. J. For. Res. 28 (1998) 863-870.

[11] Lasdon L.S., Waren A., Jain A., Ratner M., Design and testing of a generalized reduced gradient code for non-linear programming, ACM Transactions on Mathematical Software 4 (1978) 34-50.

[12] Lasdon L.S., Smith S., Solving sparse non-linear programs using GRG, ORSA J. Comput. 4 (1992) 2-15.

[13] Magnussen S., Selection index: economic weights for maximum simultaneous genetic gain, Theor. Appl. Genet. 79 (1990) 289-293.

[14] Miettinen K., Non-linear multiobjective optimization, Kluwer Academic Publishers, 1999.

[15] Namkoong G., A multiple-index selection strategy, Silvae Genet. 25 (1976) 5-6.

[16] Namkoong G., Kang H.C., Brouard J.S., Tree breeding: principles and strategies, Springer-Verlag, NY, 1988.

[17] NIMBUS, Nondifferentiable interactive multiobjective bundle-based optimization system, University of Jyväskylä, Department of Mathematical Information Technology, Finland, 2000, http://nimbus.math.jyu.fi/

[18] Page D.H., A theory for the tensile strength of paper, TAPPI J. 52 (1969) 674-681.

[19] Page D.H., A quantitative theory of the strength of wet webs, J. Pulp. Paper. Sci. 19 (1993) 175-176.

[20] QUERCUS, Quantitative genetics Ssoftware, the University of Minnesota College of Biological Sciences, 2000, http://biosci.cbs.umn.edu/ eeb/quercus.html

[21] Roberds J.H., Namkoong G., Population selection to maximize value in an environmental gradient, Theor. Appl. Genet. 77 (1989) 128-134.

[22] Rudie A.W., Morra J., St. Laurent J., Hickey K., The influence of wood and finber propertieson mechanical pulping, TAPPI J. 77 (1994) 86-89.

[23] Shaw R., Maximum likelihood approaches applied to quantitative genetics of natural populations, Evolution 41 (1987) 812-826.

[24] Zhang S.Y., Morgenstern E.K., Genetic variation and inheritance of wood density in black spruce (Picea mariana) and its relationship with growth: implications for tree breeding, Wood. Sci. Tech. 30 (1995) 63-75.

[25] Zobel B.J., vanBuijtenen J.P., Wood Variation: its causes and control, Springer-Verlag, NY, 1989.

[26] Zobel B.J., Jett J.B., Genetics of wood production, Springer-Verlag, NY, 1995. 